\title{
CATHETER BASED CLOSURE OF HYPERTENSIVE PDA(S) WITH UNCONVENTIONAL DEVICES -IMMEDIATE AND SHORT TERM FOLLOW UP
}

\begin{tabular}{|c|c|}
\hline Cardiology & \\
\hline $\begin{array}{l}\text { Mirza Mohd } \\
\text { Kamran* }\end{array}$ & $\begin{array}{l}\text { Fellow paediatric cardiology, Rabindranath Tagore Institute of cardiac science, Kolkata. } \\
{ }^{*} \text { Corresponding Author }\end{array}$ \\
\hline Mahua Roy & $\begin{array}{l}\text { Consultant paediatric cardiology, Rabindranath Tagore Institute of cardiac } \\
\text { Kolkata. }\end{array}$ \\
\hline
\end{tabular}

\section{Amitabha Chattopadhyay} Sushil Shukla
Senior consultant paediatric cardiology, Narayana superspecialty hospital, howrah. Junior consultant paediatric cardiology,Rabindranath Tagore Institute of cardiac sciences , kolkata.

\section{ABSTRACT}

Patent ductus arteriosus (PDA) is a common form of CHD, accounts for approximately $8 \%$ of congenital heart disease with the incidence of one in 2500 to 5000 live births. More common in female. It may be asymptomatic and is sometimes not diagnosed early resulting into prolonged abnormal aorto-pulmonary shunt which may result in silently progressing hypertension and left ventricular dysfunction.

This study aims to evaluate the immediate \&short-term follow up results after TCC of large PDAs with severe pulmonary arterial hypertension (PHT) in children. This is a observational study of 38 patients with Large PDA and severe PHT who were referred to this centre for treatment during the period from July 2015 to Feb 2018. After evaluating clinical and hemodynamic parameters reversibility of severe PAH was established and transcatheter closure of PDA was performed. Patients were followed up clinically and echocardiographically at 24 hours, 1 month, 3 months, 6 months, 12 months and 24 months to assess the efficacy, safety of the procedure \& its impact on PHT. Thirty eight patients, (26 females, $12 \mathrm{males})$ patients between 6 months to 16 years of age had underwent successful device closure. 18 patients had PDA sizes between 6-8 mm,12 had between $8-10 \mathrm{~mm}, 6$ had between $10-15 \mathrm{~mm}$ and only 2 patients had largest PDA more than $15 \mathrm{~mm}$ at PA end .5 patients were selected for closure with muscular VSD device. We have successfully closed 3 of our largest PDA (12 mm, 16mm and 18mm) with Post Infarct Muscular VSD Occluder measuring $20 \mathrm{~mm}, 22 \mathrm{~mm}$ and $24 \mathrm{~mm}$ respectively. TCC of hypertensive but reversible PDA is feasible. The immediate and short-term outcomes have proven this method to be safe and valid.

\section{KEYWORDS}

Congenital heart disease, device closure, hemodynamic, paediatric intervention

\section{INTRODUCTION}

Patent ductus arteriosus (PDA) is a common form of CHD, accounts for approximately $8 \%$ of congenital heart disease with the incidence of one in 2500 to 5000 live births.[1]More common in female. It may be asymptomatic and is sometimes not diagnosed early resulting into prolonged abnormal aorto-pulmonary shunt which may result in silently progressing hypertension and left ventricular dysfunction. The presence of volume overloading of the left atrium and left ventricle is an indication for closure of the defect. PDA is defined as persistent patency in term infants even after three months.[2]The shape of the PDA varies, a classification was given by Krichencko et al. [3] Since the first percutaneous closure of PDA performed by Porstmann in 1968 , various devices and coils have been introduced into clinical practice. Although, advances in transcatheter techniques have been made, there is lack of data on patient selection, technical issues, complications, and mid to long term outcomes.[4,5,6] . In this report, we present our early experiences with and the short-term outcomes of closure of hypertensive PDA using various devices.

\section{Justification Of Our Study}

Since Portsmann et al. placed first Evalon -foam plug prosthesis in 1967, every effort had been done to develop a perfect trans-catheter method for PDA occlusion. Diverse devices have been designed and some undergone modification according to the experience in their use and effectiveness. For large PDA although surgical repair is a safe, widely accepted procedure with negligible mortality but associated with morbidity, discomfort and a thoracotomy scar. In current era trans-catheter closure of PDA is modality of choice. From the period it has discovered trans-catheter closure of PDA is under continuous phase of evolution as far as technique and the closure devices are concerned. Several devices have been used in the past [7-10]. In the late 1990s, first prosthetic mesh metal as an alternative to embolization coils, was developed to occlude larger diameter channels: the Amplatzer ${ }^{\circledR}$ Duct Occluder I (ADO I) [11].

\section{MATERIALS AND METHODS}

Relevant data were obtained retrospectively from the case files and the catheterization records.Patients were classified to have severe PAH when pulmonary artery systolic pressure was more than $2 / 3$ of systolic aortic pressure basal pulmonary vascular resistance $(\mathrm{PVR})>8$ Wood units during cardiac catheterization.

\section{Patients}

All patients were admitted at least 1 day prior to the procedure for clinical, laboratory ( pre-cath profile), chest X-ray, ECG, and echocardiographic assessment. Upper and lower limb saturations were recorded at rest and after exercise in each patient. The oxygen saturation of the right lower limb ranged from 90 to $95 \%$ (Without supplemental oxygen inhalation).echocardiographic evaluation revealed the size \& anatomy of the PDA, and estimation of the pulmonary artery pressure (PAP). Patients were screened for presence of aortic coarctation and branch pulmonary artery stenosis. Doppler echocardiography (echo-Doppler) revealed systemic pulmonary arterial pressure and a left to right, or bidirectional with predominantly left to right, shunt through the duct

\section{Inclusion And Exclusion Criteria}

- Large PDA which were reversible on oximetry was included in study as per definition

- Large PDA turned out non reversible on oximetry, associated with other defects that requires surgical correction otherwise were excluded from the study

\section{Procedures}

Informed consent was obtained from the guardians of patients prior to the procedure. The procedure was performed under conscious sedation in all the patients. A single dose of intravenous antibiotic is administered (usually cefuroxime) The femoral vein and artery were cannulated percutaneously. Right heart catheterization was performed, basal systemic pressure and basal pulmonary arterial pressure were taken and $\mathrm{Qp} / \mathrm{Qs}$ and basal pulmonary arterial resistance were calculated. In those with systolic PAP ( $>75 \%$ of systemic pressure), duct was occluded with the device and the systemic and PAP were compared after the 15 min of occlusion. Any fall in systolic PAP of $>$ $20 \%$ of the baseline pressure was considered as an indicator of significant left to right shunt across duct contributing to PAH. Aortogram in the lateral projection and right anterior oblique $30^{\circ}$ were recorded using pigtail catheter to define the duct, diameter at the pulmonary (Duct size) and aortic ends, and its length were measured. If the PDA had suitable anatomy for closure, Amplatzer ductal occluders (ADO, AGA medical corporation, Plymouth, MN, USA) was used in the patients having duct size $\leq 14 \mathrm{~mm}$. If the duct was $>14 \mathrm{~mm}$, other duct occluders like ,Lifetech Scientific Ltd, Shenzen, China or 
Amplatzer muscular septal defect occluders (AMVSDO, AGA medical corporation, Plymouth, MN, USA, were used. The PDA was crossed from the pulmonary end .Delivery sheath was introduced from the venous side + over the Amplatzer super stiff guide wire (Boston Scientific, Natick, MA, USA), and was kept in the descending thoracic aorta. The device size used was the one size more as the angiographic size. Device was delivered as per the standard technique described earlier. [2],[3],[4] Aortogram was done at $10 \mathrm{~min}$ after the release to confirm device position and rule out residual shunt. Post procedure, the patients were monitored in the intensive cardiac care unit for $24 \mathrm{~h}$. A close watch was kept for any evidence of intravascular haemolysis and device embolization. Patients were discharged after 48 hours of observation. All cases were followed at 6 weeks, 3 months, 6 months and every year thereafter. Improvement in functional class and weight gain was noted. The patients were evaluated clinically for any evidence of worsening of PHT. At follow up echocardiography, the position of the device was confirmed and residual shunt if any was noted. The presence of turbulence in the left pulmonary artery (LPA) and aortic isthmus was looked for and the velocities/gradients across these structures were recorded. The PAP was estimated with tricuspid regurgitation jet on follow up. Repeat catheterization was not done in any case. Oral aspirin ( $150 \mathrm{mg}$ or $5 \mathrm{mg} / \mathrm{kg} /$ day) was given for 3 months in all cases.

\section{RESULTS}

From July 2015 to Feb 2018, 38 patients (26 females, 12males) between 6 months to 16 years underwent trans-catheter closure of large PDA ( ranging from $6 \mathrm{~mm}$ to $18 \mathrm{~mm}$ at PA end) as an alternative to standard surgical ligation with use of different devices . Out of these 1 patient was less than 1 year. 18 patients were between $4-10$ years, 17 were between $10-15$ years and only 2 were more than 15 years. In this case series 18 patients had PDA size between $6-8 \mathrm{~mm}, 12$ had between $8-10 \mathrm{~mm}, 6$ had between $10-15 \mathrm{~mm}$ and only 2 patients had largest PDAmore than $15 \mathrm{~mm}$ at PA end (table 1).

Table 1. Table Depicting Size Of Pda \& Number Of Patients.

\begin{tabular}{|l|l|}
\hline Size of PDA at PA end in $\mathbf{~ m m}$ & Numbers \\
\hline $6-8$ & $18(47.3)$ \\
\hline $8-10$ & $12(31.5)$ \\
\hline $10-15$ & $6(15.7)$ \\
\hline$>15$ & $2(5.2)$ \\
\hline Total & 38 \\
\hline
\end{tabular}

On simultaneous measurements of PA pressure and Aortic pressure only 4 patients showed PA pressure $>2 / 3$ rd of systemic pressure which further came out reversible on oximetry testing, while remaining 34 patients had PA pressure between $<2 / 3$ rd of systemic pressure with good reversibility. The pulmonary artery and aortic pressures were recorded at baseline and after 15 min of balloon occlusion. In all patients there was a significant fall in pulmonary artery systolic pressure ( $>20 \%$ of baseline) post device occlusion of PDA was considered as being indicative of reversibility of PHT ( table 2 \& figure 1)

Table 2. Table Depicting Type Of Devices Used \& Number Of Patients.

\begin{tabular}{|l|l|}
\hline Device Types & Numbers \\
\hline ADO 1 & $26(68.4)$ \\
\hline ASD Device & $2(5.2)$ \\
\hline Vascular Plug & $2(5.2)$ \\
\hline Muscular VSD Device & $5(13.1)$ \\
\hline POST MI VSD Device & $3(7.8)$ \\
\hline Total & 38 \\
\hline
\end{tabular}

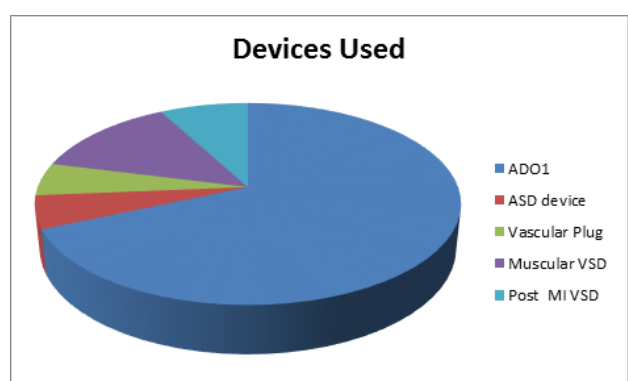

Figure 1. Comparative Distribution Of Devices Used.

As far as devices are concerned we used Amplatzer Duct Occluder
(ADOI) in 26 cases, Amplatzer Septal Occluder in 2 cases , 2 PDAs were closed with 18 and $20 \mathrm{~mm}$ Lifetech Vascular plug. In 5 other patients closure was done with muscular VSD device. We successfully closed 3 of our largest PDA (12 mm, 16mm and $18 \mathrm{~mm})$ with Post Infarct Muscular VSD Occluder measuring $20 \mathrm{~mm}, 22 \mathrm{~mm}$ and $24 \mathrm{~mm}$ respectively. All the 38 patients who were considered suitable for TCC underwent successful closure of PDA. There was no incidence of device migration or embolization. At the time of post deployment angiogram, 36 out of 38 patients showed residual shunt through the device. However, it disappeared over a period of time and there was no residual shunt in any of the patients at the time of the last follow up

\section{Complications}

No mortality noted in this study. Significant hypotension (50\% drops in aortic systolic pressure) along with ST-T changes in inferior leads were noted in five. Hemodynamic stability was regained in as soon as stiff wire was removed after placing the delivery sheath in the descending aorta. Transient loss of lower limb pulses was observed in 4 patients .At the time of pre discharge echocardiography, two patients had a mild flow acceleration in their LPA with a maximum velocity of $>$ $2 \mathrm{~m} / \mathrm{s}$ but $<2.5 \mathrm{~m} / \mathrm{s}$ while six patients had peak velocity of $>2 \mathrm{~m} / \mathrm{s}$ but less than $2.5 \mathrm{~m} / \mathrm{s}$ in the region of the aortic isthmus due to the protrusion of aortic retention disc into the aortic lumen.

\section{DISCUSSION}

Every patient with ductus and severe pulmonary hypertension should be evaluated for evidence of significant left to right shunt utilizing clinical examination, chest X ray, ECG, Echo Doppler and if necessary, hemodynamic assessment at cardiac catheterization to ensure satisfactory long term outcome after device closure [2,3]

Assessment of PVR at cardiac catheterization after administering $100 \%$ oxygen, and after nitric oxide has several limitations in a patient with PDA. [5],[6],[7] In the case of PDA, the exact site of sampling dist al to the shunt also remains controversial since the precise streaming of the ductal flow is not universal. [6]

Temporary occlusion of PDA with balloon or device has been in use to decide on contribution of left to right shunt and pulmonary vascular resistance to PAH. [2],[3],[5],[8],[9] Use of device is less cumbersome and saves time but is an expensive proposition in case the PAP does not fall or actually rises. This is a reliable test to exclude patients with borderline hemodynamic data from undergoing device closure. [12],[13], There is no consensus on the type of device to be used for closing large PDAs with severe PHT. ADO is available up to $16 \times 14$ $\mathrm{mm}$. For defects larger than $14 \mathrm{~mm}$, AMVSDO or duct occluders of other makes (Lifetech and Cocoon) can be used. These duct occluders are available up to $24 \times 22$. This is of particular importance in order to prevent any obstruction to the flow in the LPA or the aortic isthmus. Significant stenosis most often occurs in those where pre-existing LPA stenosis or aortic coarctation that has been overlooked prior to the closure of PDA.Hemolysis is a rare and well documented complication of incomplete PDA closure with significant residual shunt sometimes requiring complete closure of the shunt with the use of more coils, glue or surgery. [14] Fall of PAP in the long term is the hallmark of successful closure of PDA with severe PHT.

\section{CONCLUSIONS}

Although surgical repair of large PDA is a safe, widely accepted procedure with negligible mortality, it is associated with morbidity, discomfort and a thoracotomy scar. As an alternative to surgery transcatheter closure of PDA with different unconventional devices is a good option with better results.

\section{REFERENCES}

1. Mullins C, Pagotto L. Patet ductus arteriosus. The science and practice of pediatric :ardiology. In: Garson A, Bricker JT, Fisher DJ, Neish SR, editor. 2 ed. Philadelphic: Williams and Wilkins; 1997. p. 1181-97.

2. Mitchell SC, Korones SB, Berendes HW (1971) Congenital heart disease in 56,109 births. Incidence and natural history. Circulation 43: 323-332.

3. Krichenko A, Benson LN, Burrows P, Möes CA, McLaughlin P, et al. (1989) Angiographic classification of the isolated, persistently patent ductus arteriosus and implications for percutaneous catheter occlusion. Am J Cardiol 63: 877880

4. Bridges N, Perry S, Parness J, Keane J, Lock JE (1991). Transcatheter closure of a large patent ductus arteriosus with the clamshell septal umbrella. J Am Coll Cardiol.18(5):1297-302.

5. Cambier PA, Kirby WC, Wortham DC, Moore JW (1992). Percutaneous closure of the small (less than $2.5 \mathrm{~mm}$ ) patent ductus arteriosus using coil embolization. Am J Cardiol 69(8):815-6.

6. Chamié F, Pereira SJ, Sbaffi F, Serra Junior AH, Athayde JG (1996). Fechamento de canal arterial com molas de Gianturco. Arq Bras Cardiol.67(1):23-7. 
7. Grifka RG, Mullins CE, Gianturco C, Nihill MR, O'Laughlin MP, Slack MC, et al. (1995). New Gianturco- Grifka vascular occlusion device: initial studies in a canine model. Circulation.

8. Evidence BasedMedicine forLifetech ProductsI issue date:1st.April.2014 Version14.1

9. Lloyd TR, Fedderly R, Mendelsohn AM, Sandhu SK, Beekman RH 3rd.(1993). Transcatheter occlusion of patent ductus arteriosus with Gianturco coils. Circulation.88(4 Pt 1):1412-20

10. Lloyd TR, Beekman RH 3rd, Moore JW, Hijazi ZM, Hellenbrand WE, Sommer RJ, et al. (1995). The PDA Coil Registry Investigators: 250 patient-years follow-up. Circulation.92:1380.

11. Porstmann W, Wierny L, Warnke H, Gertsberger G, Romanuick PA (1971). Catheter closure of patent ductus arteriosus: 62 cases treated without thoracotomy. Radiol Clin North Am.9(2):201-13.

12. Rao PS, Wilson AD, Sideris EB, Chopra PS (1991). Transcatheter closure of patent ductus arteriosus with "buttoned" device: first successful clinical application in a child. ductus arteriosus with "buttoned" device: first successful clinical application in a child. Am Heart J. 121(6 Pt 1):1799-802

13. Rashkind WJ, Cuaso CC. (1979). Transcatheter closure of a patent ductus arteriosus: successful use in a $3.5 \mathrm{~kg}$ infant. Pediatr Cardiol.1(1):3-7.

14. Rashkind WJ, Mullins CE, Hellenbrand WE, Tait MA (1987). Non surgical closure of patent ductus arteriosus: clinical appli- cation of the Rashkind PDA occluder system. Circulation.75(3):583-92. 